\title{
Erratum: Unpacking physics representations: Towards an appreciation of disciplinary affordance [Phys. Rev. ST Phys. Educ. Res. 10, 020129 (2014)]
}

\author{
Tobias Fredlund, Cedric Linder, John Airey, and Anne Linder
}

(Received 8 March 2019; published 9 April 2019)

DOI: 10.1103/PhysRevPhysEducRes.15.019901

Errata have come to our attention in our article published in this journal. These occur in Table I and Figs. 6 and 7. For clarification, part of the discussion given in Sec. IV.B.2 has also been revised. The parts given below should replace the corresponding parts in the article in full.

The errata do not affect the central case made in the article, namely, that teachers can further help students discern the critically important physics aspects through unpacking the representations that are typically used in physics for a given topic, $\mathrm{RC}$ circuits being the illustrative example for the article.

\section{IV.B.2. Simplifying the circuit}

Having completed this first attempt to connect the circuit, the students struggled with getting the oscilloscope screen to show anything meaningful by, for example, trying different frequencies of the square wave input signal. This prompted Will to ask: "Have we even connected it correctly?" while carefully examining their circuit. When the input signal did not show

TABLE I. Summary of the illustrative vignette showing the sequence of connections and reconnections of the circuit that the students carried out and the oscilloscope images obtained at each stage. The signals from the function generator and the capacitor are shown in blue and yellow, respectively.

Description $\quad$ Circuit connection $\quad$ Image on the oscilloscope screen

(a) The students' first connection

(b) The students' modified connection (using a BNC T connector)
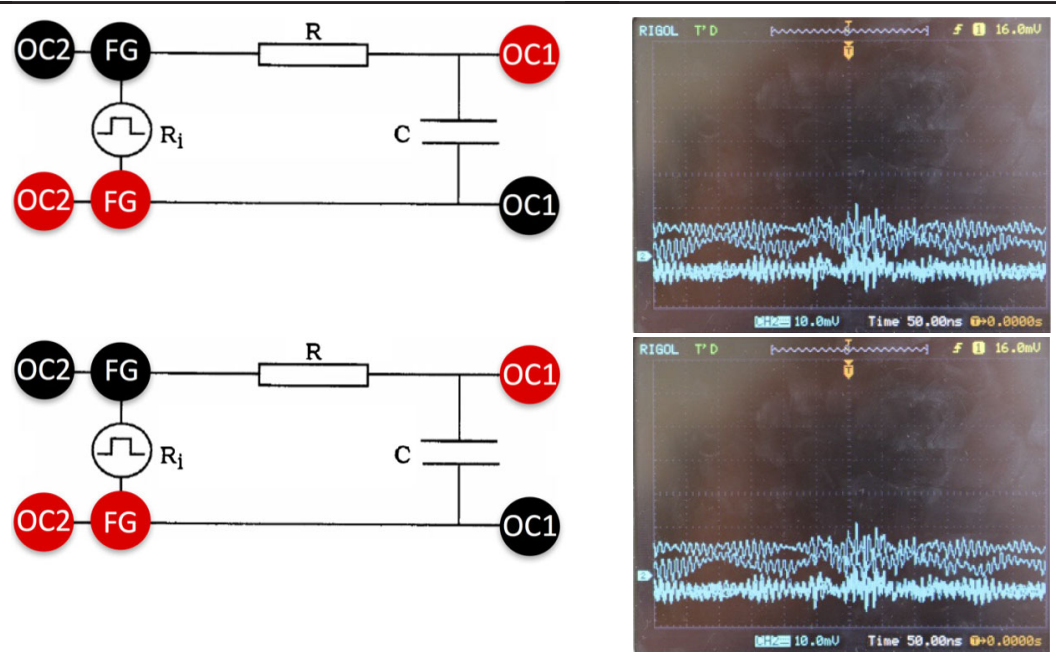

(Table continued)

*Corresponding author. tobias.fredlund@hig.se

Published by the American Physical Society under the terms of the Creative Commons Attribution 4.0 International license. Further distribution of this work must maintain attribution to the author(s) and the published articles title, journal citation, and DOI. 
TABLE I. (Continued)

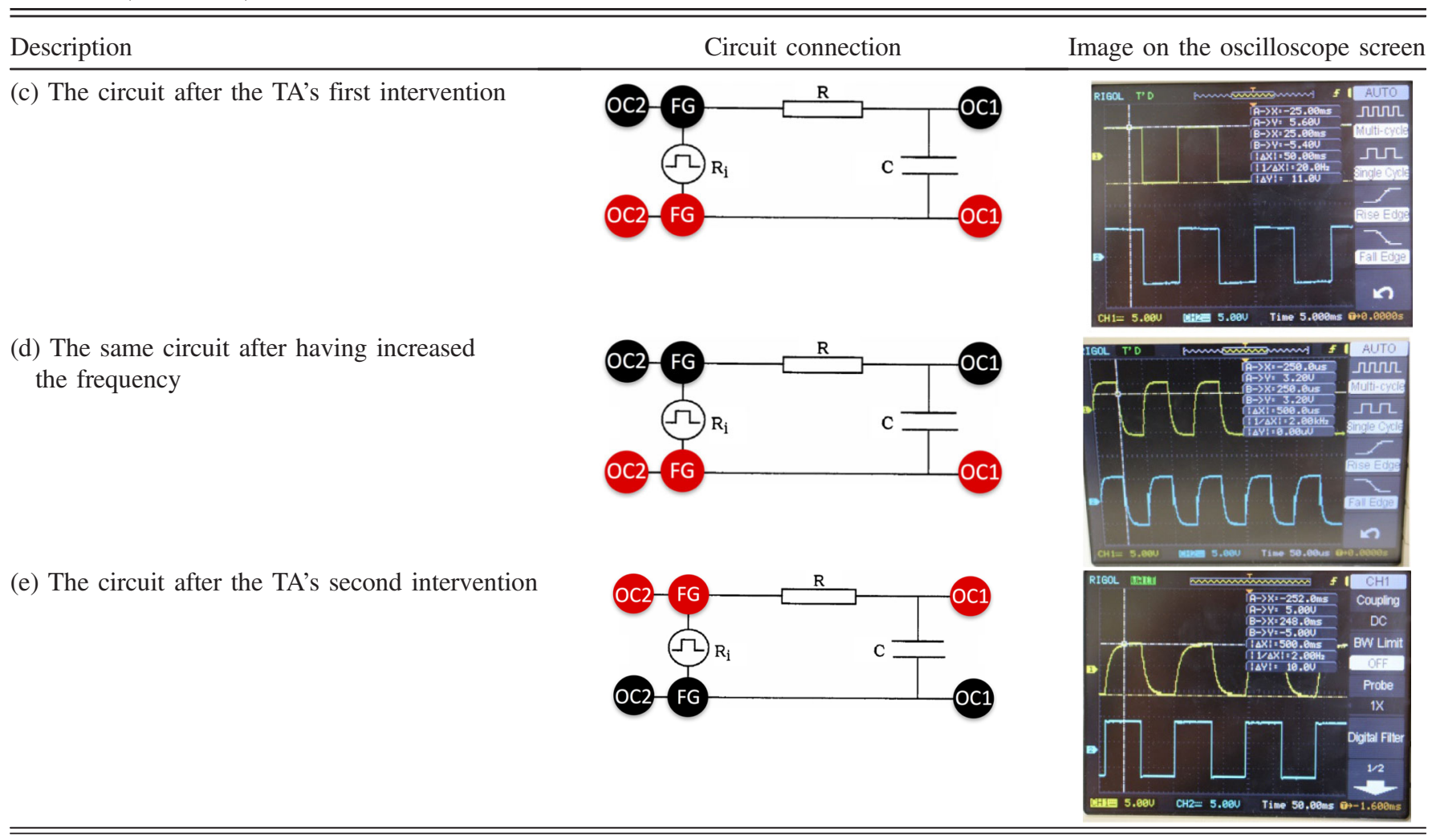

d) The same circuit after having increased
the frequency 


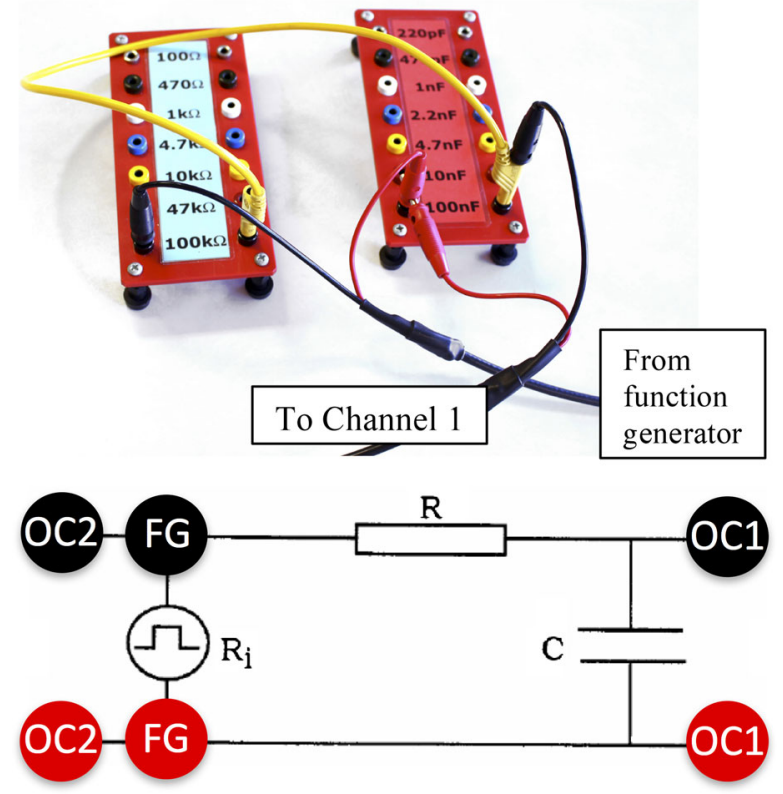

FIG. 7. A pictorial and a diagrammatic representation of the students' circuit after it had been corrected according to the TA's advice. Both "signal ends" of the cables were then connected to the same (equivalent) point in the circuit. FG refers to the function generator and OC1 and OC2 refer to the oscilloscope's Channel 1 and Channel 2, respectively.

on the oscilloscope screen, they attempted to simplify their connections by connecting the function generator directly to the oscilloscope's Channel 2 with a coaxial cable that had BNC connectors at both ends. They managed this by getting a BNC T connector (see Fig. 5) to simultaneously connect the function generator to the circuit with a split-end coaxial cable. The assumption was that the T connector would somehow "automatically" generate the correct connections for them. As shown in Fig. 6 and Table I(b), however, this could not resolve the problem and there was no change in the image provided by the oscilloscope. 